\title{
Cuttings Transport with Gas in the Highly-Deviated Horizontal Wells
}

\author{
Sun Xiaofeng, Wang Kelin*, Yan Tie, Shao Shuai and Luan Shizhu \\ College of Petroleum Engineering, Northeast Petroleum University, Daqing 163318, China
}

\begin{abstract}
Gas drilling has been widely used due to its advantages of protecting and finding oil and gas reservoir, reducing lost circulation and pipe sticking, extending the bit life, and improving rate of penetration (ROP). Cuttings transport in highly-deviated and horizontal segment is considered as an important part of the design of hydraulic parameters. In this case, poor cuttings transport will lead to stuck pipe, higher drag and torque, slower ROP, bad cementing quality, and other problems. In this study, a two-layer steady model was developed to depict cuttings transport behavior, and the sensitivity analyses were conducted. The simulations show the ratio of bed area and annular area and pressure drop decrease with the increase of pipe eccentricity or inclination, and increase with the increasing gas density or gas viscosity. But the inclination, gas density and viscosity have a minor effect on cuttings transport.
\end{abstract}

Keywords: Cuttings transport, highly-deviated horizontal well, gas drilling, cuttings bed.

\section{INTRODUCTION}

Gas drilling as one of underbalanced drilling (UBD) candidates has shown significant benefits including protection of oil and gas reservoir, minimization of lost circulation, etc, and has been used and constantly developed in the United States, Canada and some European countries from the 1980s [1]. Meanwhile, cuttings transport has continued to be a subject of interest to researchers and engineers, and the targets are focused on the minimum flow rate or carrying capability. Angel developed the first model about the minimum volume flow rate, and the model is generally referred to as the Angel model [2]. Before the 1980 s, the model was widely applied to design hydraulic parameters for gas drilling [3]. While the result obtained from the model is less than about $25 \%$ of the actual field value [1]. As a result, some modified Angle models [4, 5] and new models $[6,7]$ begin to appear. However, most models only can be valid for vertical or near vertical well, and the researches on cuttings transport in highly-deviated horizontal well are less.

Meng et al. [8] investigated the carrying cuttings capability in gas horizontal drilling, and found that the cuttings transport behavior is far different from that in gas vertical drilling. The require gas obtained by them is larger than that calculated by the widely used method by $50 \%$ $100 \%$. Subsequently, they [9] applied CFD software to conduct the analyses of flow fields on the eccentric annulus where the drill string lies on the lower wellbore wall in the horizontal segment. The results show the accumulation of cuttings is presented in the narrow gap due to the lower velocity profile, and increasing gas injection rate can improve the cuttings transport, but the enhancement level is dependent on wellbore size.

*Address correspondence to this author at the College of Petroleum Engineering, Northeast Petroleum University, Daqing 163318, China;

Tel: +860459-6503521; Fax: +860459-6503482;

E-mails:wwangkelin@163.com,wk12370@163.com
Yuan et al. [10] analyzed the drillcollar-drillpipe interface and casing-open hole interface based on fluid dynamic design for air drilling. Combined with the dynamic analysis and the aerodynamic characteristics of the wing structure, the thin wing theory was introduced to analyze the stresses exerted on the cuttings, and the minimum gas rate for effective cuttings transport during drilling high-angle horizontal well was also discussed. Based on the findings, the method and equation used to calculate the fluid dynamics parameters were proposed, and the minimum gas flow rate was obtained by analyzing the annulus pressure distribution and cuttings removal energy distribution with numerical simulation software.

Wang et al. [11] considered the gas heat exchange and wall friction effect, and analyzed the impact of temperature on gas injection rate. According to the heat balance equation, a temperature model was established for gas horizontal drilling, and the most widely used model (Guo's injection volume model) was also modified. Also, the injection volume obtained by the modified model is in agreement with field tests.

Liu et al. [12] studied the required gas velocity for cuttings to move under different wellbore angle, cutting size and friction coefficient based on bulk mechanics and gas dynamics. The result shows that it is difficult to lift cuttings in horizontal and high-angle segment where drilling string is near the lower wall of hole.

In this paper, a steady-state two-layer cuttings transport model was established based on the pneumatic transport model [13], and the effects of inclination, pipe eccentricity, etc on cuttings transport were also analyzed.

\section{MODEL HYPOTHESES}

In order to simplify the model within the range that will not deteriorate the accuracy of the model, the following hypotheses are considered in the development of a mechanical model. 
(1) Due to the action of gravitational forces, the solids deposits and eventually develops cuttings bed, and the solid concentration is $52 \%$.

(2) The drillpipe rotation effect is not considered.

(3) Cuttings size, sphericity and distribution are uniform.

(4) There is no mass transfer between the solid and liquid phases.

(5) The mass and energy exchanges between wellbore and formation are ignored.

(6) There is slip between gas phases and solids in both suspended layer and cuttings bed.

(7) The gain/loss from crumbling, cave-in, enlargement and shrinkage of wellbore are ignored.

\section{MECHANICAL MODEL FOR CUTTINGS TRANSPORT}

As seen in Fig. (1), in a certain gas flow rate, there exist both suspended layer and cuttings bed in the annulus. The mechanical model was established based on the gas-solid flow pattern.

\subsection{Continuity Equations}

Equations (1) and (2) describe the mass conservation relationship for gas phases and solids, respectively:

$A_{\mathrm{sd}} C_{\mathrm{sdg}} v_{\mathrm{sdg}}+A_{\mathrm{b}} C_{\mathrm{bg}} v_{\mathrm{bg}}=Q_{\mathrm{ginj}}$

$A_{\mathrm{sd}}\left(1-C_{\mathrm{sdg}}\right) v_{\mathrm{sdc}}+A_{\mathrm{b}}\left(1-C_{\mathrm{bg}}\right) v_{\mathrm{bc}}=Q_{\text {cinj }}$

For the gas flow rate and solid velocity in the suspended layer, the Klinzing's correlation can be used [14]:

$v_{\mathrm{sdc}}=\left(C_{\mathrm{sdg}} v_{\mathrm{sdg}}-v_{\mathrm{t}}^{0.71}\right) D_{\mathrm{sd}}^{0.019}$

$v_{\mathrm{t}}$ represents the terminal settling velocity. Based on the balance between gravitational force and drag force, the velocity can be expressed by [15]: $v_{\mathrm{t}}=\sqrt{\frac{4}{3} \frac{d_{\mathrm{p}}\left(\rho_{\mathrm{c}}-\rho_{\mathrm{g}}\right) g}{C_{\mathrm{D}} \rho_{\mathrm{c}}}}$

In this study, the used cuttings diameter is larger than $0.965 \mathrm{~mm}$ and the density is $2650 \mathrm{~kg} / \mathrm{m}^{3}$. As a result, the settling features are considered in the Newtonian region, and ignored in the Stokes and Alien region. Finally, $C_{\mathrm{D}}=0.44$.

\subsection{Momentum Equations}

Conservation of momentum relationships for the flow of gas phase and the solids can be expressed by Equations (5) and (6), respectively:

$A_{\mathrm{sd}} \frac{\Delta p}{L}=\tau_{\mathrm{sdgw}}+\tau_{\mathrm{sdgb}}+F_{\mathrm{sdcw}}+F_{\mathrm{sdcb}}+F_{\mathrm{cb}}+F_{\mathrm{sdG}}$

$A_{\mathrm{b}} \frac{\Delta p}{L}=-\tau_{\mathrm{sdgb}}-F_{\mathrm{sdcb}}+\tau_{\mathrm{bgw}}-F_{\mathrm{cb}}+F_{\mathrm{bcw}}+F_{\mathrm{bG}}$

The friction force $F_{\mathrm{cb}}$ which is generated by jumping particles on the cuttings bed can be calculated by [16]:

$F_{\mathrm{cb}}=c_{2} k_{1} \rho_{\mathrm{c}} S_{\mathrm{sdb}} L\left(1-C_{\mathrm{sdg}}\right)\left(v_{\mathrm{sdc}}-v_{\mathrm{bc}}\right) v_{\mathrm{sdc}}$

$F_{\mathrm{sdcw}}, F_{\mathrm{bcw}}$, the frictional force between wall surface and cuttings in the suspended layer or cuttings bed, $\tau_{\mathrm{sdgw}}, \tau_{\mathrm{bgw}}$, the shear stress between wall surface and gas phases in the suspended layer or cuttings bed, can be obtained by [13]:

$$
\begin{aligned}
& F_{\text {sdcw }}=\frac{f_{\text {sdcw }} c_{3} \rho_{\mathrm{c}} v_{\mathrm{sdc}}^{2}}{2 D_{\mathrm{sd}}} \frac{S_{\mathrm{sd}}}{S_{\mathrm{sd}}+S_{\mathrm{sdb}}} A_{\mathrm{sd}} L\left(1-C_{\mathrm{sdg}}\right) \\
& F_{\mathrm{bcw}}=f_{\mathrm{bcw}} F_{2 \mathrm{n}} \\
& \tau_{\mathrm{sdgw}}=\frac{f_{\mathrm{sdgw}} \rho_{\mathrm{g}} v_{\mathrm{sdg}}^{2}}{2 D_{\mathrm{sd}}} \frac{S_{\mathrm{sd}}}{S_{\mathrm{sd}}+S_{\mathrm{sdb}}} A_{\mathrm{sd}} L C_{\mathrm{sdg}} \\
& \tau_{\mathrm{bgw}}=\frac{f_{\mathrm{bgw}} \rho_{\mathrm{g}} v_{\mathrm{bg}}^{2}}{2 D_{\mathrm{b}}} \frac{S_{\mathrm{b}}}{S_{\mathrm{b}}+S_{\mathrm{sdb}}} A_{\mathrm{b}} L C_{\mathrm{bg}}
\end{aligned}
$$
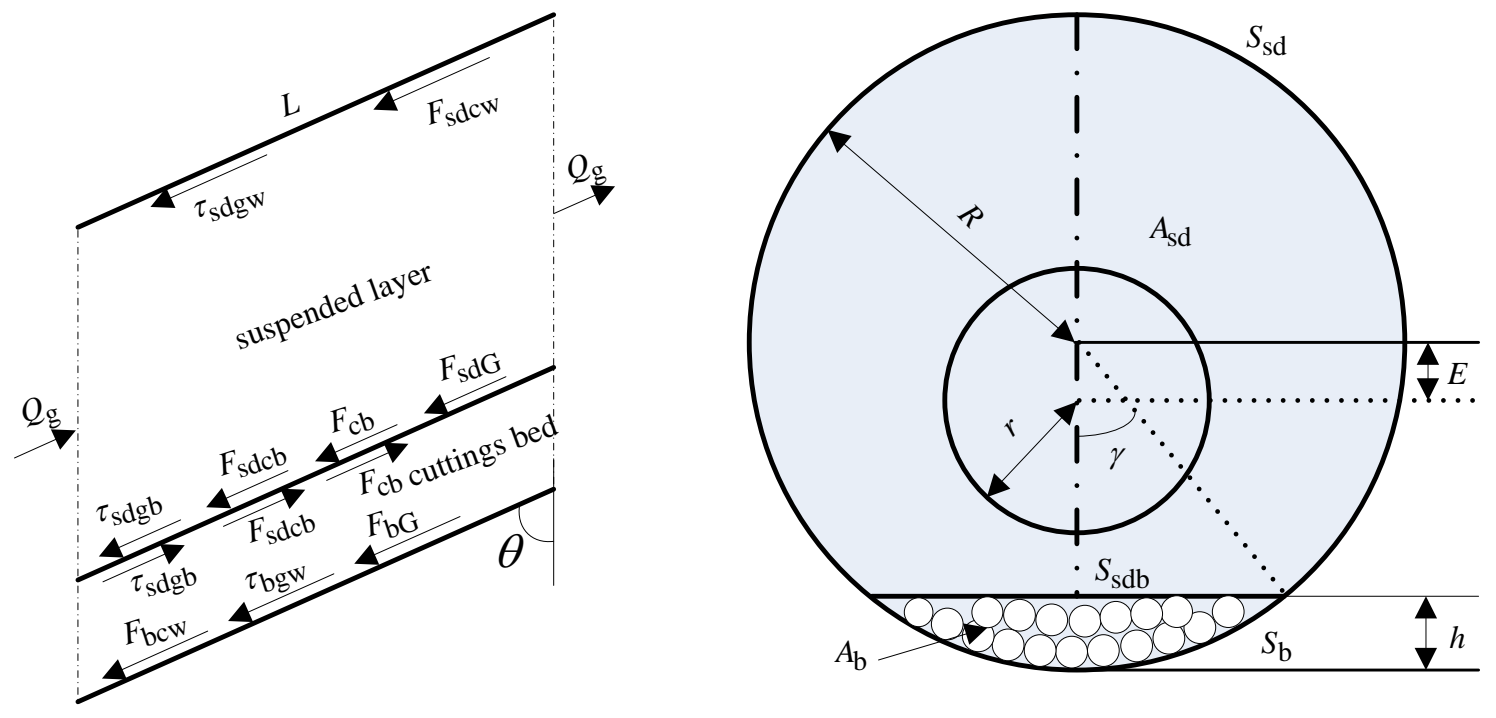

Fig. (1). Schematic diagram of the two-layer model. 
In the study, $f_{\mathrm{bcw}}=0.51$ [17], and other coefficients for the above frictional forces or shear stresses are:

$$
\begin{aligned}
& f_{\text {sdgw }}=0.3164 \mathrm{Re}_{\mathrm{sdg}}^{-0.25} \\
& f_{\text {bgw }}=0.3164 \mathrm{Re}_{\mathrm{bg}}^{-0.25}
\end{aligned}
$$

$f_{\text {sdcw }}=0.117 \frac{1-C_{\text {sdg }}}{C_{\text {sdg }}^{3}}\left(\left(1-C_{\text {sdg }}\right) \frac{\mathrm{Re}_{\mathrm{t}}}{\mathrm{Re}_{\mathrm{c}}} \frac{v_{\mathrm{sdg}}}{\sqrt{g D_{\mathrm{sd}}}}\right)^{-1.15}$

where $\quad \operatorname{Re}_{\text {sdg }}=\frac{v_{\text {sdg }} D_{\text {sd }} \rho_{\mathrm{g}}}{\mu_{\mathrm{g}}} \quad \operatorname{Re}_{\mathrm{bg}}=\frac{v_{\mathrm{bg}} D_{\mathrm{b}} \rho_{\mathrm{g}}}{\mu_{\mathrm{g}}} \quad \operatorname{Re}_{\mathrm{t}}=\frac{v_{\mathrm{t}} d_{\mathrm{p}} \rho_{\mathrm{g}}}{\mu_{\mathrm{g}}}$ $\operatorname{Re}_{\mathrm{c}}=\frac{\left(v_{\mathrm{sdg}}-v_{\mathrm{sdc}}\right) d_{\mathrm{p}} \rho_{\mathrm{g}}}{\mu_{\mathrm{g}}}$

The normal pressure acting on the wall surface $F_{2 \mathrm{n}}$ is composed of the effect of the submerged weight of the particles $F_{\text {wn }}$, and the transmission of stress from the interface $F_{\mathrm{n}}[13]$ :

$$
\begin{aligned}
F_{2 \mathrm{n}}= & F_{\mathrm{wn}}+F_{\phi \mathrm{n}} \\
F_{\mathrm{wn}}= & 0.5 g D^{2} L \cos \theta\left(1-C_{\mathrm{bg}}\right)\left(\rho_{\mathrm{c}}-\rho_{\mathrm{g}}\right)(\sin \gamma-\gamma \cos \gamma) \\
F_{\phi \mathrm{n}}= & \frac{c_{1} g A_{\mathrm{sd}} D L \cos \theta \gamma\left(1-C_{\mathrm{sdg}}\right)\left(\rho_{\mathrm{c}}-\rho_{\mathrm{g}}\right)}{\left(1-C_{\mathrm{bg}}\right) S_{\mathrm{sdb}}} \\
& +2 c_{2} k_{2}^{2} v_{\mathrm{bc}}^{2} D L \gamma \rho_{\mathrm{c}} \cos \theta\left(1-C_{\mathrm{sdg}}\right)
\end{aligned}
$$

The shear stresses $F_{\mathrm{sdcb}}, \tau_{\mathrm{sdgb}}$ which are generated by the solids [14] and the gas phases [16] in the suspended layer can be given by:

$$
\begin{aligned}
& F_{\mathrm{sdcb}}=c_{1} f_{\mathrm{cc}} g A_{\mathrm{sd}} L\left(1-C_{\mathrm{sdg}}\right)\left(\rho_{\mathrm{c}}-\rho_{\mathrm{g}}\right) \\
& \tau_{\mathrm{sdgb}}=f_{\mathrm{sdgb}} \rho_{\mathrm{g}} \frac{\left(v_{\mathrm{sdg}}-v_{\mathrm{bc}}\right)^{2}}{2 D_{\mathrm{sd}}} \frac{S_{\mathrm{sdb}}}{S_{\mathrm{sd}}+S_{\mathrm{sdb}}} A_{\mathrm{sd}} L C_{\mathrm{sdg}}
\end{aligned}
$$

where $f_{\text {cc }}$ is internal friction factor among solids, and $f_{\text {cc }}=0.62$ [17]. It is assumed that the roughness of cuttings bed is the half of solid diameter, and the friction factor $f_{\mathrm{sdgb}}$ is expressed by:

$$
f_{\mathrm{sdgb}}=8\left(2.5 \ln \left(6.69 \frac{D_{\mathrm{sd}}}{d_{\mathrm{p}}}\right)\right)^{-2}
$$

In equation (7) and (17), the coefficients $k_{1}, k_{2}$ are related to collision angle $\alpha$ and lifting angle $\beta$ before and after the collision among the particles on the cuttings bed. White and Schulz advise to use the following correlations to depict the relation between $\alpha$ and $\beta$ [13]:

$\beta=21.8 \alpha^{0.316}$

$k_{1}=(\cot \beta-\cot \alpha) \tan \alpha, k_{2}=\tan \alpha$

In equation (7), (17) and (18), $c_{1}$ and $c_{2}$ are the distribution coefficients, and are written by [13]:

$c_{1}=1-\frac{C_{\mathrm{av}}-C_{\mathrm{bg}}}{C_{\mathrm{sdg}}-C_{\mathrm{bg}}}$
$c_{2}=\left(1-\frac{C_{\mathrm{av}}-C_{\mathrm{bg}}}{C_{\mathrm{sdg}}-C_{\mathrm{bg}}}\right)\left(\frac{C_{\mathrm{av}}-C_{\mathrm{bg}}}{C_{\mathrm{sdg}}-C_{\mathrm{bg}}}\right)$

where $C_{\mathrm{av}}=\left(C_{\mathrm{sdg}} A_{\mathrm{sd}}+C_{\mathrm{bg}} A_{\mathrm{b}}\right) / A$

$F_{\mathrm{sdG}}, F_{\mathrm{bG}}$, the gravitational force for suspended layer and cuttings bed, are expressed by:

$F_{\text {sdG }}=A_{\text {sd }} L\left(\rho_{\mathrm{g}} C_{\text {sdg }}+\rho_{\mathrm{c}}\left(1-C_{\text {sdg }}\right)\right) \cos \theta$

$F_{\mathrm{bG}}=A_{\mathrm{b}} L\left(\rho_{\mathrm{g}} C_{\mathrm{bg}}+\rho_{\mathrm{c}}\left(1-C_{\mathrm{bg}}\right)\right) \cos \theta$

\subsection{Geometrical Parameters}

For the pipe totally buried under the cuttings bed, the geometrical parameters are listed as follows:

$$
\begin{aligned}
& A_{\mathrm{sd}}=A(\pi-\gamma)-\sin (\pi-\gamma) \cos (\pi-\gamma) r^{2} \\
& A_{\mathrm{b}}=A-A_{\mathrm{sd}} \\
& S_{\mathrm{sd}}=2 r \sin (\pi-\gamma) \\
& S_{\mathrm{b}}=S-S_{\mathrm{sd}} \\
& S_{\mathrm{sdb}}=2 r \sin (\pi-\gamma) \\
& D_{\mathrm{b}}=\frac{4 A_{\mathrm{b}}}{S_{\mathrm{b}}+S_{\mathrm{sdb}}} \\
& D_{\mathrm{sd}}=\frac{4 A_{\mathrm{sd}}}{S_{\mathrm{sd}}+S_{\mathrm{sdb}}}
\end{aligned}
$$

For the pipe partially buried in the cuttings bed and above the bed, the geometrical parameters are given in reference [18].

\subsection{Critical Velocity for Particle on the Cuttings Bed}

In the annuli, the forces acting on cuttings include gravitational force, drag force, pressure gradient, Saffman lift force, Basset force, etc [19]. As shown in Fig. (2), the

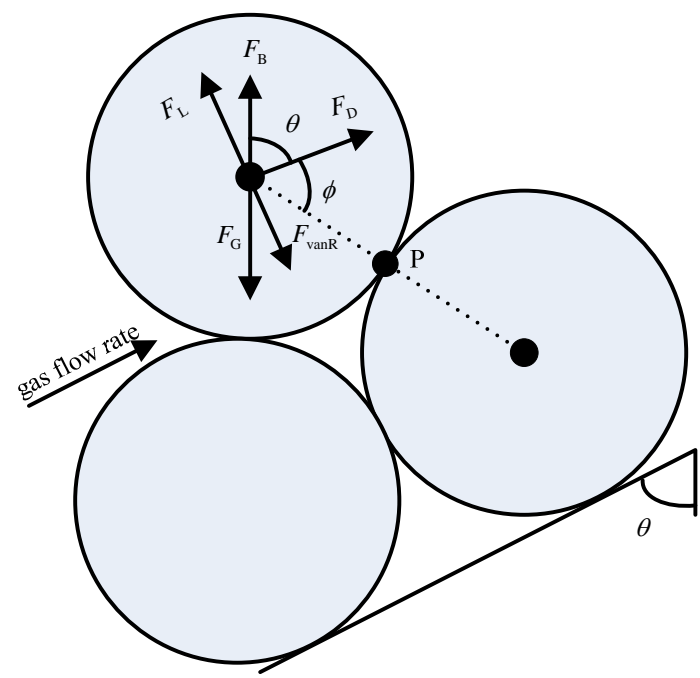

Fig. (2). The forces acting on the particle on a cuttings bed [21]. 
gravitational force $F_{\mathrm{G}}$, drag force $F_{\mathrm{D}}$, lift force $F_{\mathrm{L}}$, Van der Waals force $F_{\text {vanR }}$ are considered. Under the action of these forces, the particles on the cuttings bed may be moved in rolling or lifting method, therefore, the corresponding velocity are the rolling velocity and lifting velocity, respectively. Finally, the minimum value between rolling velocity and lifting velocity takes as the critical velocity for particle on the cuttings bed [20].

Rolling velocity $v_{\mathrm{r}}$ :

$F_{\mathrm{L}} \frac{d_{\mathrm{p}}}{2} \cos \phi+F_{\mathrm{B}} \frac{d_{\mathrm{p}}}{2} \sin (\theta+\phi)+F_{\mathrm{D}} \frac{d_{\mathrm{p}}}{2} \sin \phi>$

$F_{\text {vanR }} \frac{d_{\mathrm{p}}}{2} \cos \phi+F_{\mathrm{G}} \frac{d_{\mathrm{p}}}{2} \sin (\theta+\phi)$ where $F_{\mathrm{G}}=\frac{\pi d_{\mathrm{p}}^{3}}{6} \rho_{\mathrm{c}} g$

$$
\begin{aligned}
& F_{\mathrm{B}}=\frac{\pi d_{\mathrm{p}}^{3}}{6} \rho_{\mathrm{g}} g \\
& F_{\mathrm{D}}=0.5 C_{\mathrm{D}} \rho_{\mathrm{g}} v_{\mathrm{r}}^{2} A \\
& F_{\mathrm{L}}=0.5 C_{\mathrm{L}} \rho_{\mathrm{g}} v_{\mathrm{r}}^{2} A \\
& F_{\text {vanR }}=-\frac{\sin \phi \times 10^{-7}}{2.37 d_{\mathrm{p}}^{0.54}}
\end{aligned}
$$

Lifting velocity $v_{1}$ :

Table 1. Base Data for Simulations in Highly-Deviated Horizontal Well

\begin{tabular}{|c|c|c|c|c|c|}
\hline Wellbore Diameter & Drillpipe Diameter & Solid Density & Solid Injection Velocity & Gas Injection Velocity & Collision Angle \\
\hline \hline $215.9 \mathrm{~mm}$ & $127 \mathrm{~mm}$ & $2650 \mathrm{~kg} / \mathrm{m}^{3}$ & $0.002 \mathrm{~kg} / \mathrm{m}^{3}$ & $3 \mathrm{~kg} / \mathrm{m}^{3}$ & $7.5^{\circ}$ \\
\hline
\end{tabular}

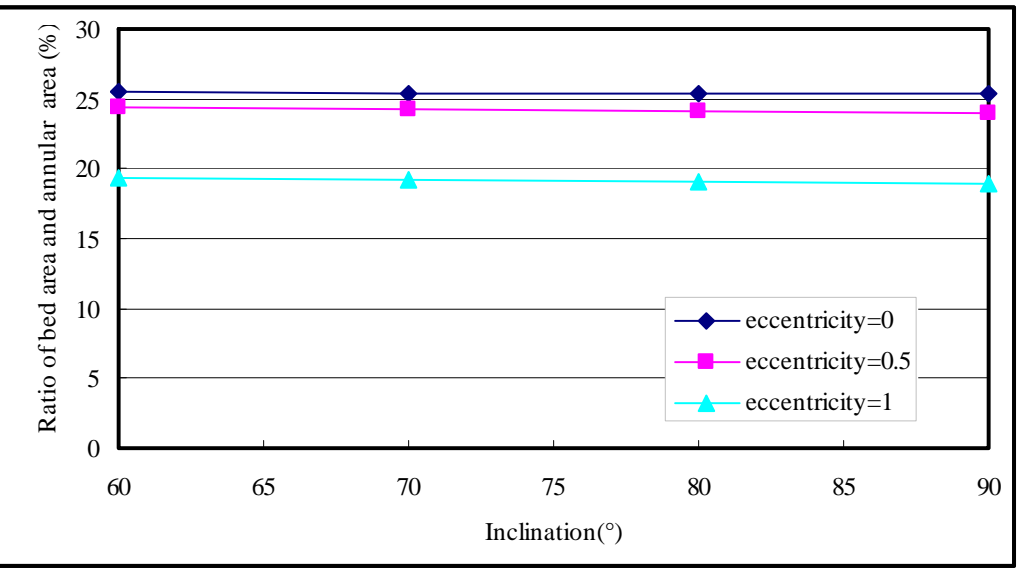

Fig. (3). Ratio of bed area and annular area variation with pipe eccentricity in different inclinations.

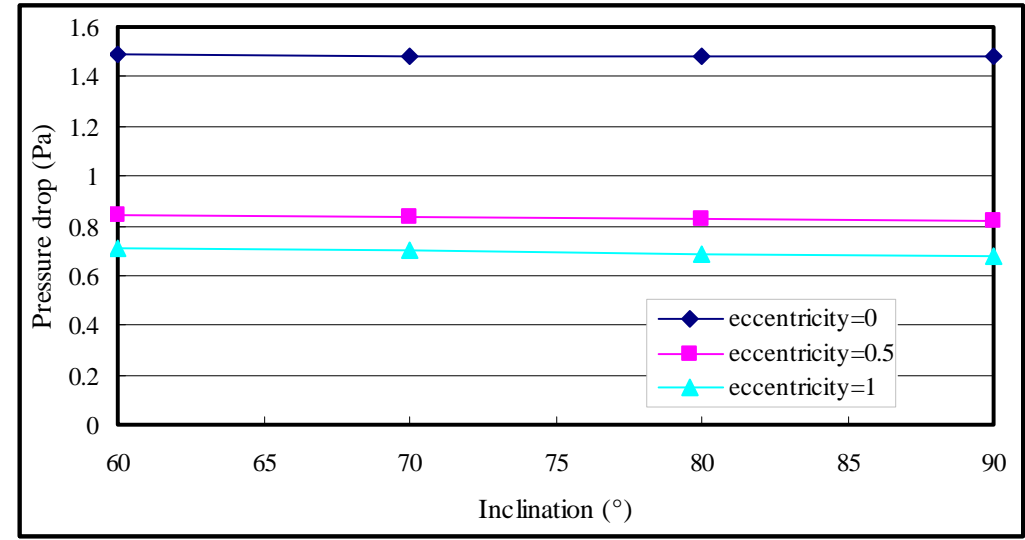

Fig. (4). Pressure drop variation with pipe eccentricity in different inclinations 


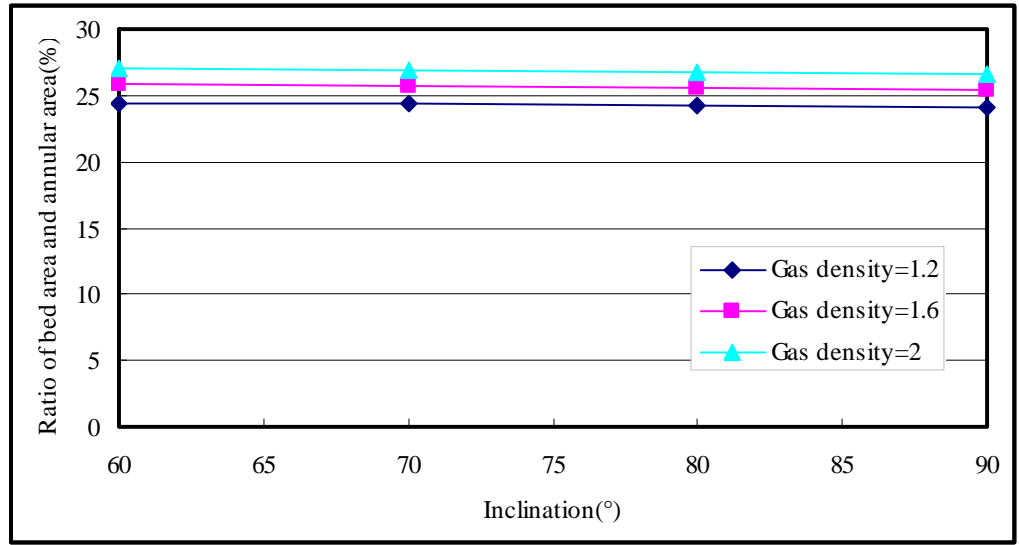

Fig. (5). Ratio of bed area and annular area variation with gas density in different inclinations.

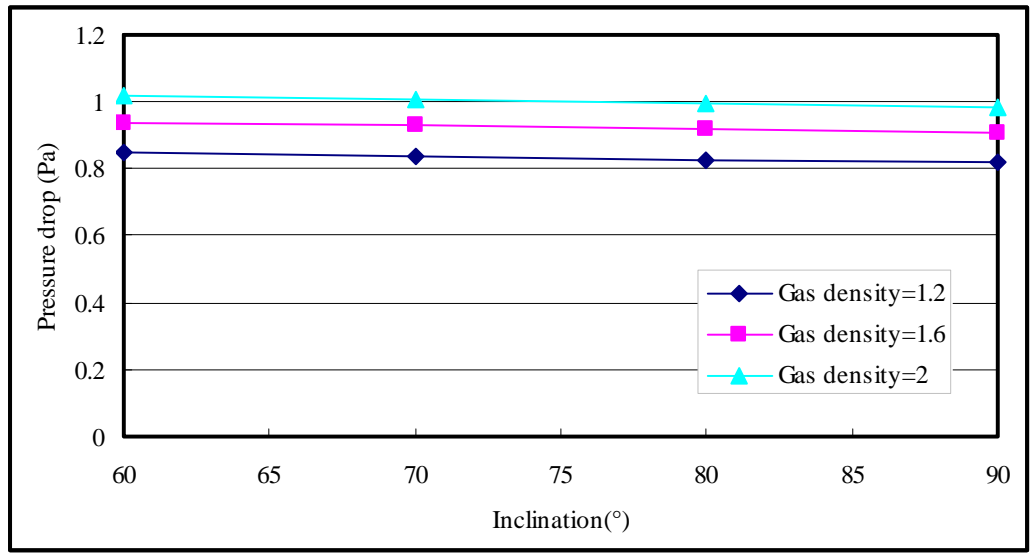

Fig. (6). Pressure drop variation with gas density in different inclinations.

$F_{\mathrm{L}} \sin \theta+F_{\mathrm{b}} \cos \theta>F_{\mathrm{vanR}} \sin \theta+F_{\mathrm{G}}$

Critical velocity for the particle $v_{\mathrm{R}}$ :

$v_{\mathrm{R}}=\min \left(v_{\mathrm{r}}, v_{1}\right)$

\section{MODEL DISCUSSIONS \\ RESULTS \\ AND}

Based on the above mechanical model, C\# was applied to develop the program to calculate the annular pressure drop and the ratio of annular area and bed area. Sensitivity analyses were conducted to show the effects of pipe eccentricity, gas density, gas viscosity, and inclination on the pressure drop and the ratio. The base data used for the simulations are shown in Table $\mathbf{1 .}$

Figs. $(3,4)$ show the effects of pipe eccentricity on the ratio of bed area and annular area and annular pressure drop. When the pipe eccentricity keeps constant, the ratio and pressure drop slightly decrease by increasing the inclination. In the same inclinations, the ratio and pressure drop also decrease with the increasing pipe eccentricity. The may explain that the more eccentricity, the bigger suspended layer area, which leads to a little flow resistance. In addition, the reduced amplitude of the ratio is more between 0.5 and 1 , and the reduced amplitude of the pressure drop is more between 0 and 0.5 .

Figs. $(5,6)$ indicate the effects of gas density on the ratio of bed area and annular area and annular pressure drop. In the same inclinations, the ratio and pressure drop increase with the increase of gas density, but the increase amplitudes are rather small. The means that gas density is not the key factor for the design of hydraulic parameters for gas drilling.

Figs. (7, 8) illustrate the effects of gas viscosity on the ratio of bed area and annular area and annular pressure drop. When the inclinations are constant, the ratio and pressure drop increase with the increase of gas viscosity, but the increase amplitudes are rather small. The higher gas viscosity can generate big buoyancy and high flow friction loss, but the value of gas viscosity is less than liquid phase. As a result, the gas viscosity is not the key parameter for gas drilling. 


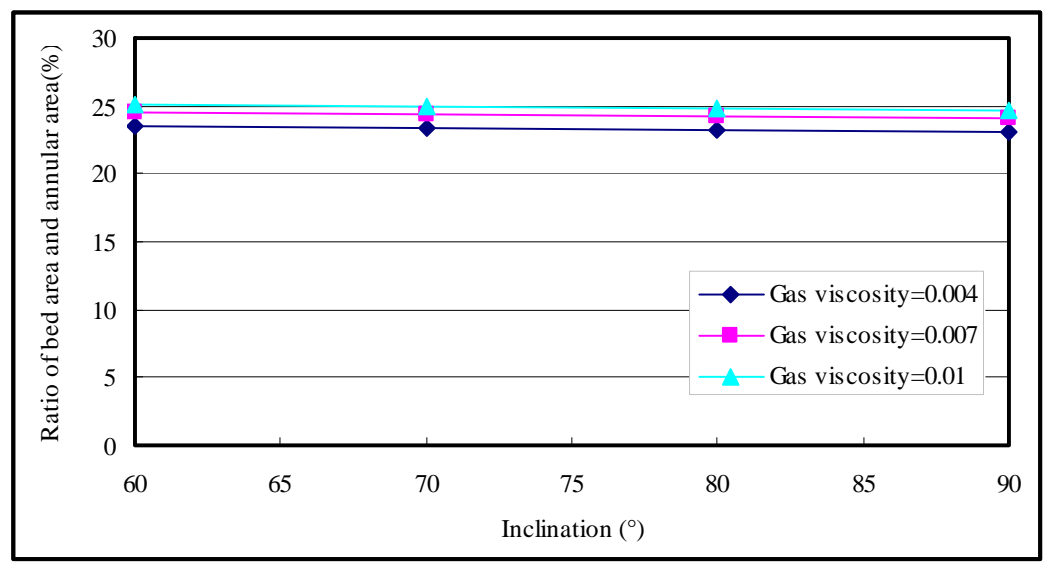

Fig. (7). Ratio of bed area and annular area variation with gas viscosity in different inclinations.

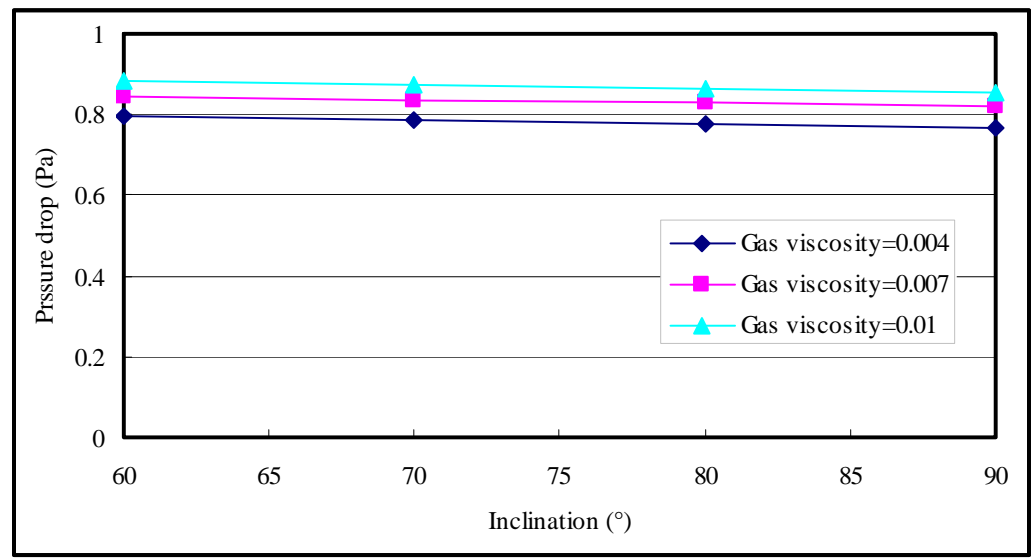

Fig. (8). Pressure drop variation with gas viscosity in different inclinations.

\section{CONCLUSIONS}

A two-layer steady mechanical model for cuttings transport with gas in highly-deviated and horizontal segments has been established. The model can be used to predict the annular pressure drop and the ratio of bed area and annular area in special conditions.

When the pipe eccentricity keeps constant, the ratio of bed area and annular area and pressure drop slightly decrease with the increase at inclination. In the same inclinations, the ratio and pressure drop also decrease with the increasing pipe eccentricity. Also, the ratio and pressure drop increase with the increase of gas density or gas viscosity, but the increase amplitudes are rather small.

Even though the inclination, pipe eccentricity, gas density and viscosity have a certain effect on cuttings transport, the pipe eccentricity can be considered as a key factor for designing hydraulic parameters of gas drilling.

\section{NOMENCLATURE}

A $=$ Cross-sectional area, $\mathrm{m}^{2}$

$\mathrm{C}=$ Volumetric concentration, dimensionless

$\mathrm{C}_{\mathrm{L}}=$ Lift coefficient, dimensionless

$\mathrm{C}_{\mathrm{D}}=$ Drag coefficient, dimensionless

$\rho \quad=$ Density, $\mathrm{kg} / \mathrm{m}^{3}$

$\mathrm{D} \quad=$ Hydraulic diameter, $\mathrm{m}$

$\mathrm{d}_{\mathrm{p}} \quad=$ Particle diameter, $\mathrm{m}$

g = Gravity, N/kg

$\mathrm{L}=$ Length of cuttings bed, $\mathrm{m}$

$\operatorname{Re} \quad=$ Reynolds number, dimensionless

$\mathrm{S} \quad=$ Wetted perimeter, $\mathrm{m}$

$\Delta \mathrm{p} \quad=$ Pressure drop, $\mathrm{Pa}$ 


$$
\begin{array}{ll}
\mathrm{v} & =\text { Flow rate, } \mathrm{m} / \mathrm{s} \\
\mathrm{Q}_{\text {ginj }} & =\text { Gas injection flow rate, } \mathrm{kg} / \mathrm{s} \\
\mathrm{Q}_{\text {cinj }} & =\text { Solid injection flow rate, } \mathrm{kg} / \mathrm{s} \\
\gamma & =\text { Contact angle between the bed and hole wall, }{ }^{\circ} \\
\theta & =\text { Inclination, }{ }^{\circ} \\
& =\text { Angle of repose, } \\
\mu & =\text { Viscosity, } \mathrm{Pa} \cdot \mathrm{s}
\end{array}
$$

\section{SUBSCRIPTS}

$$
\begin{array}{ll}
\mathrm{sd} & =\text { Suspended layer } \\
\mathrm{sdg} & =\text { Gas phases in the suspended layer } \\
\mathrm{b} & =\text { Cuttings bed } \\
\mathrm{bc} & =\text { Cuttings in the bed } \\
\mathrm{sdb} & =\text { Interface between suspended layer and bed } \\
\mathrm{g} & =\text { Gas phase } \\
\mathrm{c} & =\text { Cuttings }
\end{array}
$$

\section{CONFLICT OF INTEREST}

The authors confirm that this article content has no conflict of interest.

\section{ACKNOWLEDGEMENTS}

The support of the National Natural Science Foundation of China (No. 51174043, No. 51204056) are gratefully acknowledged.

\section{REFERENCES}

[1] Zhu, H.J.; Lin, Y.H.; Meng, Y.F.; Zhao, S.J.; Luo, F.Q. Influence of Relevant Parameters on Hole Cleaning and Pipe String Erosion in Air Drilling. In: SPE Oil and Gas Indian Conference and Exhibition; 20-22 Jan 2010; Mumbai: India, 2010.

[2] Angel, R.R. Volume requirements for air and gas air drilling. $J$. Pharm. Technol., 1957, 9, 325-330.

[3] Supon, S.B.; Adewumi, M.A.; Fairchild, N. Measurement and Analysis of the Pressure Drop in a Vertical Annulus in a Simulated Air Drilling Operation. In: SPE Eastern Regional Meeting; 21-23 Oct 1987; Pittsburgh, Pennsylvania, 1987.

[4] Jochen, J.E.; Lnacaster, D.E. Reservoir Characterization of an Eastern Kentucky Devonian Shales Well Using a Naturally
Fractured, Layered Description. In: SPE Gas Technology Symposium; 28-30 June 1993; Calgary, Alberta, Canada, 1993.

Laubach, S.E.; Doherty, E. Oriented Drilled Sidewall Cores for Natural Fracture Evaluation. In: SPE Annual Technical Conference and Exhibition; 3-6 Oct 1999; Houston, Texas, 1999.

Li, Y.F.; Meng, Y.F.; Nie, Z.Y.; Zhang, J. The mechanisms of increasing ROP during air drilling. Petrol. Drill. Tech., 2006, 34(4), 9-11.

Lian, Z.H.; Lin, T.J.; Meng, Y.F. Dynamic simulation of rockbreaking process during gas drilling. Natural Gas Ind., 2008, 28(6), 88-89.

8] Meng, Y.F.; Lian, Z.H.; Li, Y.J.; Liang, H.; Wu, S.R.; Wu, X.Z.; Chen, G.; Xiao, X.Y. Research on the cuttings-carried ability in gas horizontal drilling and its application to well Baiqian-111H. Nat. Gas Ind., 2005, 25(8), 50-53.

[9] Meng, Y.F.; Lian, Z.H.; Liang, H.; Li, Y.J.; Wu, S.R.; Wu, X.Z.; Chen, G.; Xiao, X.Y. CFD numerical simulation research on cuttings-carried capability in gas horizontal drilling. Nat. Gas Ind., 2005, 25(7), 50-52.

[10] Yuan, Z.G.; Zhou, K.J.; Meng, Y.F.; Wan, Y.S.; Zhong, S.Q. Calculating the minimum gas volume used in high-angle horizontal wells during gas drilling. Nat. Gas Ind., 2007, 27(4), 65-68.

[11] Wang, Y.; Han, H.; Yan, T.; Bi, X.L.; Xin, Y. Modification of gas injection model for horizontal wells during gas drilling. J. Daqing Petrol. Inst., 2009, 33(3), 69-71.

[12] Liu, G.H.; Song, T.Y.; Li, J. Analysis of cuttings transportation during drilling gas horizontal wells. Petrol. Drill. Tech., 2009, 37(5), 26-29.

[13] Qiu, P.H. Study on the Pneumatic Transport of High Concentration Pulverized Coal. Thesis, Harbin Institute of Technology, China, 2002.

[14] Huang, B. Pneumatic Transport; Shanghai Science and Technology Press: Shanghai, 1984.

[15] Li, J.S.; Zhou, X.J. Pneumatic Conveying Theory and Application; China Machine Press: Beijing, 1991

[16] Fang, D.Q. Two-Phase Hydrodynamics; National University of Defense Technology Press: Changsha, 1988

[17] Duan, G.B.; Hu, S.G.; Zhao, J.; Wang, L.J.; Shen, J.G. Study on flow process of gas-solid two- phase stratified flow in horizontal pipe . Chin. Q. Mech., 2008, 29(3), 468-474.

[18] Gavlgnet, A.A.; Sobey, I.J. Model aids cuttings transport prediction. $J P T$, 1989, 41(9), 916-921.

[19] Lian, G.S. Introduction to Multiphase Flow, Zhejiang University Press: Hangzhou, 1989.

[20] Wang, Z.M. Fluid Mechanical in Petroleum Engineering; Petroleum Industry Press: Beijing, 2008

[21] Duan, M.Q.; Miska, S.; Yu, M.J.; Takach, N.; Ahmed, R.; Zettner, C. Critical conditions for effective sand-sized solids transport in horizontal and high-angle wells. SPE Drill. Completion, 2009, 24(2), 229-238. 